\title{
OPEN Correlation of staging and risk factors with cardiovascular autonomic neuropathy in patients with type II diabetes mellitus
}

\author{
Muhanad M. Dhumad ${ }^{1}$, Farqad B. Hamdan ${ }^{2}{ }^{2}$, Mahmood S. Khudhair ${ }^{3}$ \& \\ Hisham Y. Al-Matubsi $4 \bowtie$
}

The impairment of cardiovascular autonomic control among the underdiagnosed complication of diabetes mellitus (DM) with a high prevalence rate of up to $60 \%$ in type 2 DM (T2DM). Cardiac autonomic neuropathy (CAN) is an independent risk factor for cardiovascular mortality, arrhythmia, silent ischemia, any major cardiovascular event, and heart failure. We aimed to evaluate cardiovascular autonomic activity by different physiological maneuvers, study risk factors for diabetic CAN including age, gender, duration of diabetes, body mass index (BMI), and glycemic control, and correlate CAN stage with risk factors. One hundred and forty-two T2DM patients consisted of 62 males and 80 females and 100 volunteers as a control sample. Cardiac autonomic functions were assessed by Ewing's tests. Glycated hemoglobin (HbA1c), body weight, height, body mass index (BMI), and waist-hip ratio (WHR) were also measured. Cardiovascular autonomic functions and Ewing scores were significantly different in people with diabetes when compared with control healthy subjects. Ewings test values and Ewing scores were significantly different between diabetics with and without CAN and within patients with different CAN staging. People with diabetes with CAN have a significantly longer duration of disease when compared to those without CAN. A strong association has been found between CAN severity and patient age, duration of disease, HbA1c severity, and the WHR $(P<0.001)$ but not with BMI. The duration of disease and HbA1c level appear to be associated with the development of CAN ( $P=0.001$ and $P=0.008$, respectively). The poorer glycemic control and the longer the duration of the disease, the higher the prevalence of CAN in T2DM. Age, duration of disease, WHR, and HbA1c are well correlated with the severity of CAN. Parasympathetic impairment is more sensitive to the detection of autonomic dysfunctions than do sympathetic impairment.

Diabetes mellitus (DM) is a chronic metabolic syndrome characterized by the presence of hyperglycemia ${ }^{1}$. Chronic hyperglycemia is associated with long-term microvascular complications manifested as retinopathy, nephropathy, and neuropathy ${ }^{2}$. Diabetic neuropathy includes peripheral neuropathy and autonomic neuropathy ${ }^{3}$. Disease duration and level of glycemic control are amongst the important causative factors which donated to the development of autonomic neuropathy (AN) in T2DM patients ${ }^{4}$.

In T2DM, AN is still an underdiagnosed cause of morbidity and mortality, particularly when it involves the cardiac functions in terms of cardiac autonomic neuropathy (CAN). This CAN result in cardiovascular dysfunction which is accompanied by the progression to myocardial ischemia, coronary artery disease, and stroke $e^{5,6}$.

CAN prevalence increases substantially with diabetes duration in T2DM (up to 60\% after 15 years) ${ }^{7}$. Besides, CAN is present in some patients with prediabetes, insulin resistance, or metabolic syndrome ${ }^{8}$. Moreover, data validates an association between CAN and glucose variability, specifically in the hypoglycemic category ${ }^{9}$.

In T2DM, assessment of CAN symptoms and signs should be accomplished at the time of diagnosis, particularly for those with poor glycemic control (HbAlc $>7 \%$ ), presence of major cardiovascular disease risk factor, or additional chronic complications of $\mathrm{DM}^{4,6}$.

\footnotetext{
${ }^{1}$ Section of Pharmacy, Baghdad College of Medical Sciences, Baghdad, Iraq. ${ }^{2}$ Department of Physiology, College of Medicine, Al-Nahrain University, Baghdad, Iraq. ${ }^{3}$ Endocrinology Section, Department of Medicine, College of Medicine, Al-Nahrain University, Baghdad, Iraq. ${ }^{4}$ Department of Pharmacology and Medical Sciences, University of Petra, Amman, Jordan. ${ }^{\boxplus}$ email: almatubsi@yahoo.com
} 
We aimed to evaluate the autonomic cardiovascular function in patients with T2DM, the potential correlation between CAN and risk factors, and to associate CAN staging with risk factors.

\section{Methods}

A cross-sectional study conducted from December 2018 to August 2019 in the College of Medicine, Al-Nahrain University, and Al-Imamian Al-Kadhmiyain Medical City, Baghdad, Iraq. The study was approved by the Institutional Review Board (IBR) of the College of Medicine, Al-Nahrain University (Decision number: $\mathrm{mmm} / 155$ : Date: 11/12/2018), and informed consent was obtained from all the participants. All participants were reminded that their participation was voluntary, and they had the right to withdraw from the research at any stage.

Subjects. One hundred and forty-two patients with T2DM who attended a diabetic clinic of 62 males and 80 females aged 41 to 68 years $(53.35 \pm 7.83$ years) were studied. The duration of their illness ranges from 1 to 15 years $[(5.39 \pm 4.75$ years $)$, median $=6$ years, interquartile range $=8$ years $]$. Diagnosed cases of T2DM included in the study were those with symptoms of diabetes plus a random blood glucose concentration $\geq 200 \mathrm{mg} / \mathrm{dL}$, fasting plasma glucose $\geq 126 \mathrm{mg} / \mathrm{dL}$, and 2 -h plasma glucose $\geq 200 \mathrm{mg} / \mathrm{dL}$ during the oral glucose tolerance test ${ }^{10}$.

People with diabetes with uncontrolled hypertension, ischemic heart disease, valvular heart disease, arrhythmia, including atrial fibrillation heart failure, severe illness such as malignancy and severe infection, liver cirrhosis, gestational diabetes, severe hypoglycemia, alcoholism, and those on beta-blocker medication were excluded from the study.

Another one hundred age- and sex-matched healthy subjects composed of 39 males and 61 females serve as the control group. Their age ranges from 35 to 65 years $(51.73 \pm 8.81$ years $)$.

Medical history and examination. A detailed medical history and clinical examination were done by senior Diabetologist. Bodyweight, height, BMI, and WHR have been recorded. Fasting plasma glucose, postprandial plasma glucose, and HbAlc have been measured.

The BMI used to divide the subjects studied into underweight $(<18)$, normal $(18-<25)$, overweight $(25-<30)$ and obese (30 and above). Normal WHR range for males $=<0.9$ and females $=<0.85^{11}$.

Patients with $\mathrm{HbA} 1 \mathrm{c}$ levels between $4.4 \%$ and $6.4 \%$ considered to be a good control group, those with $\mathrm{HbA} 1 \mathrm{c}$ levels between $6.5 \%$ and $8.4 \%$ considered to be a moderate control group, and those with HbA1c levels $8.5 \%$ or higher rated as a poor control group ${ }^{12}$.

Blood pressure (BP) was measured twice using a mercury sphygmomanometer while the subject in a sitting position and the mean of the two readings was used for further analysis.

Cardiac autonomic functions. Cardiac autonomic functions were tested by 4 standard Ewing non-invasive tests ${ }^{13}$ using multi-parameter electrocardiography (ECG) patient monitor (S/N 60,107,112,602) manufactured by Bestmed Technology Limited (China). Patients were asked to fast for $12 \mathrm{~h}$ before the procedure and to avoid taking antidepressants, neuroleptics, caffeine, nicotine, antihistamines, smoking, or alcohol. The tests were conducted between 7:00 a.m. and 9:00 a.m. in a quiet environment with a steady temperature of between $22-24^{\circ} \mathrm{C}$. The tests are:

1. Autonomous parasympathetic function tests for cardiovascular control, including the following:

(a) Heart rate (HR) response to a deep breathing test:

While the subject was in a supine position with all ECG leads attached, they were asked to breathe normally for $2 \mathrm{~min}$, and then asked to perform a maximum of 6 deep breaths in $1 \mathrm{~min}$. Exhalation: inspiration (E: I) ratio was obtained using the following formula:

$\mathrm{E}$ : $\mathrm{I}$ ratio = mean value of the longest $\mathrm{R}-\mathrm{R}$ interval during the expiration/mean value of the shortest $\mathrm{R}-\mathrm{R}$ interval during inspiration.

(b) Immediate heart rate (HR) response to standing: During ECG recording, the subject was asked to lie quietly for $3 \mathrm{~min}$, then asked to stand up and remain motionless (a point was identified on the ECG paper to indicate the standpoint). The 30:15 ratio was calculated by taking the ratio of the R-R interval at the 30 th beat and 15 th beat after standing.

2. Sympathetic autonomic function tests for adrenergic vascular regulation including the following:

(a) Blood pressure (BP) response to standing:

Patient BP was measured while they were lying down quietly and again when they stood up 1-2 min after standing. The postural decrease in BP after 2 min was taken as the difference between BP (systolic and diastolic $\mathrm{BP}$ ) lying and the BP (systolic and diastolic BP) standing.

(b) BP response to sustained handgrip testing (BP response to static exercise):

The subject was asked to apply handgrip pressure for $1 \mathrm{~min}$ at $30 \%$ of the maximum voluntary contraction and, at the same time, changes in BP were observed using a sphygmomanometer. The difference between the diastolic BP just before the contraction was released, and the handgrip started was taken as a measure of the response.

Variation in HR during deep breathing (E: I ratio) was considered normal if it was $\geq 1.21$ and abnormal if it was $\leq 1.10$; the value of immediate $H R$ response to standing was considered normal when it was $\geq 1.04$ and abnormal when it was $\leq 1.00$; the value of $\mathrm{BP}$ response to standing was considered normal at $\leq 10$ and abnormal at $\geq 30$, and the value of BP response to sustained handgrip was considered normal at $\geq 16$ and abnormal at $\leq 10^{4}$. Each of these 4 tests was assigned a score of 0 for normal, 0.5 for borderline, and 1 for abnormal results, and the sum of these 4 tests was the Ewing score used to assess the severity of CAN ${ }^{14}$. To look for a sympathetic or parasympathetic condition, only abnormal and normal values were taken plus borderline cases were considered normal. Therefore, subjects with 2 abnormal HR-based tests were considered having parasympathetic neuropathy. 


\begin{tabular}{|c|c|c|c|}
\hline Variable & $\begin{array}{l}\text { Controls } \\
\mathrm{n}=100\end{array}$ & $\begin{array}{l}\text { Diabetic patients } \\
n=142\end{array}$ & $p$-value \\
\hline Age (years) & $51.73 \pm 8.81$ & $53.35 \pm 7.83$ & $0.109 \dagger$ \\
\hline \multicolumn{4}{|l|}{ Gender } \\
\hline Male & $39(39 \%)$ & $62(43.66 \%)$ & $0.469 \ddagger$ \\
\hline Female & $61(61 \%)$ & $80(56.34 \%)$ & \\
\hline Weight (Kg) & $82.85 \pm 10.28$ & $84.16 \pm 10.64$ & $0.061 \dagger$ \\
\hline Height $(\mathrm{cm})$ & $167.94 \pm 14.09$ & $170.6 \pm 12.85$ & $0.116 \dagger$ \\
\hline Body mass index $\left(\mathrm{kg} / \mathrm{m}^{2}\right)$ & $29.16 \pm 4.6$ & $29.68 \pm 3.78$ & $0.334 \dagger$ \\
\hline Waist/hip ratio & $0.93 \pm 0.128$ & $0.92 \pm 0.074$ & $0.093 \dagger$ \\
\hline \multicolumn{4}{|l|}{ Current smoking } \\
\hline Yes & $18(18 \%)$ & $34(23.94 \%)$ & $0.268 \ddagger$ \\
\hline No & $82(82 \%)$ & $108(76.06 \%)$ & \\
\hline \multicolumn{4}{|l|}{ CAN tests } \\
\hline HR response (E: I ratio) & $1.246 \pm 0.065$ & $1.129 \pm 0.135$ & $<0.001 \dagger$ \\
\hline HR response (30:15 ratio) & $1.094 \pm 0.036$ & $1.024 \pm 0.10$ & $<0.001 \dagger$ \\
\hline $\mathrm{BP}$ response to standing $(\mathrm{mmHg})$ & $7.2 \pm 2.5$ & $13.345 \pm 11.3$ & $<0.001 \dagger$ \\
\hline $\mathrm{BP}$ response to sustained handgrip ( $\mathrm{mmHg}$ ) & $19.64 \pm 1.05$ & $16.556 \pm 4.73$ & $<0.001 \dagger$ \\
\hline Ewing score & $0.075 \pm 0.239$ & $1.359 \pm 1.467$ & $<0.001 \dagger$ \\
\hline
\end{tabular}

Table 1. Baseline characteristics of the study population. $\mathrm{DM}=$ diabetes mellitus; $\mathrm{HR}=$ heart rate; $\mathrm{E}$ : $\mathrm{I}=$ expiration: inspiration; $\mathrm{BP}=$ blood pressure, $\mathrm{CAN}=$ cardiac autonomic neuropathy; $\dagger \mathrm{t}$-test $\ddagger$ chi-square.

In the case of sympathetic neuropathy, at least one abnormal test result of two BP-based tests was used to denote sympathetic neuropathy ${ }^{4,15}$.

Statistical analysis. The Social Sciences Statistical Package (SPSS, version 25) was used for statistical analysis. Continuous variables were tested for normality (Shapiro Wilk test) and were found to be normally distributed. They were therefore expressed as mean $\pm \mathrm{SD}$ and analyzed with an independent $\mathrm{t}$-test or variance analysis (ANOVA). These variables were expressed as numbers and frequency and analyzed with Chi-square. The association of each variable with the development of CAN was analyzed by calculating the odds ratio (OR) with its corresponding 95\% confidence interval (CI) using univariate and multivariate logistic regression. A p-value of $<0.05$ was considered statistically significant.

Ethics approval. The study was performed under the declaration of Helsinki (2008) and the Dutch Medical Research involving Human Subjects Act (WMO).

Ethics statement. Al-Nahrain University -Baghdad, Iraq. The study approved by the Institutional Review Board (IBR) of the College of Medicine, Al-Nahrain University (Decision number: mmm/155: Date: 11/12/2018). The consent obtained in written.

\section{Results}

Characteristics of the studied population. Table 1 shows no significant differences in age, weight, height, BMI, WHR, and current smoking between people with diabetes and the control group. The overall values of the autonomic cardiovascular tests and the Ewing scores were different between the two groups studied. HR response to deep breathing (E: I ratio), HR response to standing up (30:15 ratio), and sustained handgrip $(\mathrm{mmHg})$ was significantly decreased in people with diabetes compared to control subjects $(\mathrm{p}<0.001)$. On the other hand, BP's response to standing $(\mathrm{mmHg})$ and Ewing scores was significantly higher in people with diabetes compared to control subjects $(\mathrm{p}<0.001)$.

The cardiovascular autonomic tests. Cardiovascular autonomic tests for the two groups studied were presented in Table 2. An abnormal HR response to deep breathing (E: I ratio) was found in 50\% of patients versus only $4 \%$ of healthy subjects $(p<0.001)$, abnormal HR response when standing up (30:15 ratio) in $42.25 \%$ of patients versus $1 \%$ of the healthy subject $(p<0.001)$, abnormal orthostatic hypotension in $24.65 \%$ of patients versus none $(0 \%)$ of the healthy subjects $(p<0.001)$, and finally, abnormal response to sustained handgrip in $14.79 \%$ patients versus none $(0 \%)$ of the healthy subjects $(p<0.001)$.

Patient's clinical data. People with diabetes were classified according to the cardiac autonomic tests into those with CAN and comprised $75(52.82 \%)$ patients and $67(47.18 \%)$ patients without CAN. Eighty (56.3\%) of the patients had DM for $\leq 5$ years, $31(21.83 \%)$ for $6-10$ years $(21.83 \%)$, and $31(21.83 \%)$ for $>10$ years (median $=6$ years, interquartile range $=8$ years). The study also divided the patients into three subgroups based 


\begin{tabular}{|c|c|c|c|c|}
\hline \multicolumn{2}{|l|}{ Test } & \multirow{2}{*}{\begin{tabular}{|l|}
$\begin{array}{l}\text { Controls } \\
\mathbf{n}=\mathbf{1 0 0}\end{array}$ \\
$4(4 \%)$ \\
$96(96 \%)$
\end{tabular}} & \multirow{2}{*}{\begin{tabular}{|l|}
$\begin{array}{l}\text { Diabetic patients } \\
\mathbf{n}=\mathbf{1 4 2}\end{array}$ \\
$71(50 \%)$ \\
$71(50 \%)$ \\
\end{tabular}} & \multirow{2}{*}{\begin{tabular}{|l}
$p$-value \\
$<0.001 \ddagger$
\end{tabular}} \\
\hline $\begin{array}{l}\text { HR response } \\
\text { (E: I ratio) }\end{array}$ & $\begin{array}{l}\text { Abnormal } \\
\text { Normal }\end{array}$ & & & \\
\hline $\begin{array}{l}\text { HR response } \\
\text { (30:15 ratio) }\end{array}$ & $\begin{array}{l}\text { Abnormal } \\
\text { Normal }\end{array}$ & $\begin{array}{l}1(1 \%) \\
99(99 \%)\end{array}$ & $\begin{array}{l}60(42.25 \%) \\
82(55.75 \%)\end{array}$ & $<0.001 \ddagger$ \\
\hline $\mathrm{BP}$ response to standing & $\begin{array}{l}\text { Abnormal } \\
\text { Normal }\end{array}$ & \begin{tabular}{|l|}
$0(0 \%)$ \\
$100(100 \%)$
\end{tabular} & $\begin{array}{l}35(24.65 \%) \\
107(75.35 \%)\end{array}$ & $<0.001+$ \\
\hline Sustained handgrip & $\begin{array}{l}\text { Abnormal } \\
\text { Normal }\end{array}$ & \begin{tabular}{|l|}
$0(0 \%)$ \\
$100(100 \%)$
\end{tabular} & \begin{tabular}{|l|}
$21(14.79 \%)$ \\
$121(85.21 \%)$
\end{tabular} & $<0.001 \ddagger$ \\
\hline
\end{tabular}

Table 2. Cardiovascular autonomic tests of the study population. $\mathrm{DM}=$ diabetes mellitus; $\mathrm{HR}=$ heart rate; $\mathrm{E}$ : $\mathrm{I}=$ expiration: inspiration; $\mathrm{BP}=$ blood pressure, $\ddagger$ chi-square.

\begin{tabular}{|c|c|c|c|}
\hline \multirow[b]{2}{*}{ Variables } & \multicolumn{2}{|c|}{$\begin{array}{l}\text { Diabetic patients } \\
\mathrm{n}=142\end{array}$} & \multirow[b]{2}{*}{$p$-value } \\
\hline & $\begin{array}{l}\text { With CAN } \\
\mathrm{n}=75\end{array}$ & $\begin{array}{l}\text { Without CAN } \\
\mathrm{n}=67\end{array}$ & \\
\hline Age, years & $53.79 \pm 6.66$ & $53.43 \pm 6.12$ & $0.882 \dagger$ \\
\hline \multicolumn{4}{|l|}{ Gender } \\
\hline Females & $42(56 \%)$ & $38(56.72 \%)$ & $0.932 \ddagger$ \\
\hline Males & $33(44 \%)$ & $29(43.28 \%)$ & \\
\hline Duration of DM, years & $8.95 \pm 4.19$ & $1.544 \pm 1.01$ & $<0.001 \dagger$ \\
\hline$\leq 5$ & $14(18.67 \%)$ & $66(98.51 \%)$ & $<0.001+$ \\
\hline $6-10$ & $30(40 \%)$ & $1(1.49 \%)$ & $<0.001$ 末 \\
\hline$>10$ & $31(43.33 \%)$ & $0(0 \%)$ & $<0.001 \ddagger$ \\
\hline HbA1c (\%) & $9.025 \pm 1.37$ & $8.10 \pm 1.13$ & $0.141 \dagger$ \\
\hline $4.4-6.4 \%$ & $0(0 \%)$ & $5(7.46 \%)$ & 0.013 末 \\
\hline $6.5-8.4 \%$ & $30(40 \%)$ & $39(58.21 \%)$ & $0.01 \ddagger$ \\
\hline$\geq 8.5 \%$ & $45(60 \%)$ & $23(34.33 \%)$ & 0.006 韦 \\
\hline BMI $\left(\mathrm{Kg} / \mathbf{m}^{2}\right)$ & $29.70 \pm 2.77$ & $29.75 \pm 4.68$ & $0.936 \dagger$ \\
\hline WHR & $0.93 \pm 0.07$ & $0.89 \pm 0.06$ & $0.162 \dagger$ \\
\hline HR response (E:I ratio) & $1.014 \pm 0.087$ & $1.247 \pm 0.035$ & $<0.001 \dagger$ \\
\hline HR response (30:15 ratio) & $0.962 \pm 0.089$ & $1.094 \pm 0.055$ & $<0.001 \dagger$ \\
\hline BP response to standing $(\mathrm{mmHg})$ & $19.13 \pm 12.9$ & $6.865 \pm 2.436$ & $<0.001 \dagger$ \\
\hline BP response to sustained handgrip $(\mathrm{mmHg})$ & $15.027 \pm 5.845$ & $18.286 \pm 1.943$ & $<0.001 \dagger$ \\
\hline Ewing score & $2.493 \pm 1.143$ & $0.089 \pm 0.193$ & $<0.001 \dagger$ \\
\hline
\end{tabular}

Table 3. Demographic and Ewing's tests values of diabetic patients with and without CAN. CAN=cardiac autonomic neuropathy; $\mathrm{BMI}=$ body mass index; $\mathrm{WHR}=$ waist/hip ratio; $\mathrm{HR}=$ heart rate; $\mathrm{E}$ : $\mathrm{I}=$ expiration: inspiration; $\mathrm{BP}=$ blood pressure, $\dagger \mathrm{t}$-test; $\neq$ chi-square.

on the glycemic control level; five (3.52\%) patients had HbAlc $<6.4 \%, 69$ (48.59\%) had HbA1c between $6.5 \%$ and $8.4 \%$, and $68(47.8 \%)$ had $\mathrm{HbAlc}>8.4 \%$.

There was no evidence of a difference in age, HbAlc, BMI, and WHR between the two groups in general. However, people with diabetes with CAN have a longer duration of illness than those without CAN $(p<0.001)$. Concerning the frequency of CAN in terms of diabetic control, it was evident that with poor diabetic control, the frequency of CAN increases substantially to reach its maximum with $\mathrm{HbAlc} \geq 8.5 \%$ with a significant difference $(p=0.006)$.

Furthermore, given the frequency of CAN in terms of duration of diabetes, the number of people with diabetes is almost doubled when the duration was $6-10$ years and $>10$ years compared to $<5$ years (Table 3 ).

Table 3 also shows significantly higher HR response to deep breathing (E: I ratio), HR response to standing (30:15 ratio), and sustained handgrip $(\mathrm{mmHg})$ in those without CAN as compared to those with $\mathrm{CAN}(\mathrm{p}<0.001)$. On the other hand, the BP response to standing $(\mathrm{mmHg})$ and Ewing score was significantly higher in people with diabetes with CAN as compared to those without CAN $(p<0.001)$.

Based on positive Ewing's tests, parasympathetic neuropathy (criterion: two abnormal functions) was seen in 56 (39.44\%) cases, while sympathetic neuropathy (criterion: abnormal result in one of the sympathetic function tests) was detected in $36(25.35 \%)$ people with diabetes. 


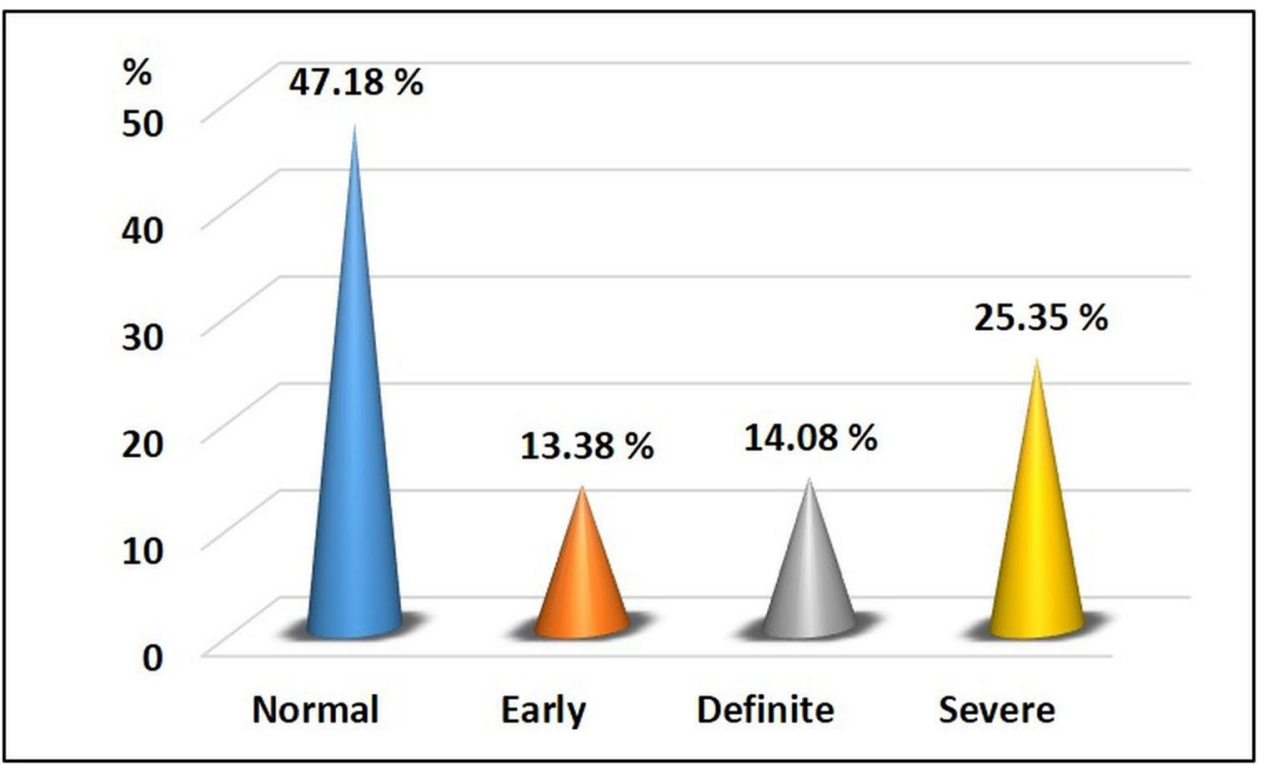

Figure 1. Staging of cardiac autonomic neuropathy in the diabetic patient.

\begin{tabular}{|c|c|c|c|c|}
\hline \multirow[b]{2}{*}{ Characteristic } & \multicolumn{3}{|l|}{$\begin{array}{l}\text { CAN staging } \\
n=75\end{array}$} & \multirow[b]{2}{*}{ P-Value } \\
\hline & $\begin{array}{l}\text { Early } \\
n=19\end{array}$ & $\begin{array}{l}\text { Definite } \\
n=20\end{array}$ & $\begin{array}{l}\text { Severe } \\
n=36\end{array}$ & \\
\hline Age (years) & $51.13 \pm 6.72^{\mathrm{a}}$ & $53.2 \pm 5.3^{\mathrm{a}}$ & $59.28 \pm 5.14^{\mathrm{b}}$ & $0.028 \dagger$ \\
\hline \multicolumn{5}{|l|}{ Gender } \\
\hline Male & $8(42.1 \%)$ & $13(65 \%)$ & $12(33.33 \%)$ & 0.072 \\
\hline Female & $11(57.9 \%)$ & $7(35 \%)$ & $24(66.67 \%)$ & \\
\hline BMI $\left(\mathrm{Kg} / \mathrm{m}^{2}\right)$ & $28.63 \pm 3.56$ & $28.9 \pm 2.12$ & $30.89 \pm 2.54$ & 0.422 \\
\hline WHR & $0.90 \pm 0.07^{\mathrm{a}}$ & $0.92 \pm 0.07^{\mathrm{a}}$ & $0.96 \pm 0.06^{\mathrm{b}}$ & 0.04 \\
\hline \multicolumn{5}{|l|}{ Mean HbAlc \% } \\
\hline $4.4-6.4 \%$ & $0(0 \%)$ & $0(0 \%)$ & $0(0 \%)$ & 0.122 \\
\hline $6.5-8.4 \%$ & $10(52.63 \%)$ & $15(75 \%)$ & $5(13.89 \%)$ & $<0.001 \neq$ \\
\hline$\geq 8.5 \%$ & $9(47.37 \%)$ & $5(25 \%)$ & $31(86.11 \%)$ & $<0.001 \neq$ \\
\hline \multicolumn{5}{|c|}{ DM duration (years) } \\
\hline$<5$ & $14(73.68 \%)$ & $4(20 \%)$ & $0(0 \%)$ & $<0.001 \ddagger$ \\
\hline $6-10$ & $5(26.32 \%)$ & $12(60 \%)$ & $13(36.11 \%)$ & $<0.001 \ddagger$ \\
\hline$>10$ & $0(0 \%)$ & $4(20 \%)$ & $23(63.89 \%)$ & $<0.001+$ \\
\hline
\end{tabular}

Table 4. Characteristic of diabetic patients with CAN (using ANOVA test). CAN: cardiac autonomic neuropathy; BMI: body mass index; WHR: waist-hip ratio; DML diabetes mellitus. $\dagger \mathrm{t}$-test, $\ddagger$ chi-square. Different small letters indicate significant differences.

CAN staging. Cardiac autonomic neuropathy was categorized into four different stages according to Ewing's criteria $^{14}$ : Normal $=$ when all the cardiovascular autonomic tests were negative and consisted of 67 patients $(47.18 \%)$; Early $=$ when one of the three HR tests was abnormal and consisted of 19 patients (13.38\%); Definite $=$ when two HR tests were abnormal and included $20(14.08 \%)$; and Severe $=$ when two HR tests and one or both BP tests were abnormal and consisted 36 (25.35\%) as shown in Fig. 1.

The characteristics of the seventy-five people with diabetes when classified according to CAN staging were presented in Table 4. Patient age and WHR within the severe group were significantly different from those in the early and definite groups ( $p=0.028$ and $p=0.04$ respectively); while there was no significant difference $(p=0.422)$ in the BMI within the three subgroups.

According to glycemic control, none of the patients have normal HbAlc at any stage of CAN. For the moderate glycemic control group, $52.63 \%$ of the people with diabetes had early CAN, 75\% have definite CAN, while only $13.89 \%$ have severe CAN. For the poor glycemic control group, $47.37 \%$ of patients had early CAN, $25 \%$ had definite CAN and $86.11 \%$ of patients had severe CAN $(p=0.001)$.

In terms of duration of illness, for those of $<5$ years duration, $73.68 \%$ have an early CAN, $20 \%$ have definite CAN and none have severe CAN. Considering the $6-10$ years duration group, $26.32 \%$ had early CAN, $60 \%$ had 


\begin{tabular}{|c|c|c|c|c|c|}
\hline \multirow[b]{2}{*}{ Cardiovascular autonomic test } & \multicolumn{4}{|c|}{$\begin{array}{l}\text { Diabetics patients } \\
\mathrm{n}=142\end{array}$} & \multirow[b]{2}{*}{$p$-value } \\
\hline & $\begin{array}{l}\text { Normal } \\
n=67\end{array}$ & $\begin{array}{l}\text { Early } \\
n=19\end{array}$ & $\begin{array}{l}\text { Definite } \\
n=20\end{array}$ & $\begin{array}{l}\text { Severe } \\
\mathbf{n}=36\end{array}$ & \\
\hline HR response (E: I ratio) & $1.247 \pm 0.347^{\mathrm{a}}$ & $1.065 \pm 0.115^{\mathrm{b}}$ & $1.005 \pm 0.06^{\mathrm{c}}$ & $0.975 \pm 0.072^{c}$ & $<0.001$ \\
\hline HR response (30:15 ratio) & $1.095 \pm 0.055^{\mathrm{a}}$ & $1.053 \pm 0.079^{\mathrm{b}}$ & $0.952 \pm 0.068^{c}$ & $0.927 \pm 0.067^{\mathrm{c}}$ & $<0.001$ \\
\hline $\mathrm{BP}$ response to standing $(\mathrm{mmHg})$ & $6.865 \pm 2.436^{\mathrm{a}}$ & $7.633 \pm 2.565^{\mathrm{a}}$ & $7.25 \pm 2.552^{\mathrm{a}}$ & $31.81 \pm 5.231^{\mathrm{b}}$ & $<0.001$ \\
\hline BP response to sustained handgrip (mmHg) & $18.269 \pm 1.943^{\mathrm{a}}$ & $18.526 \pm 1.837^{\mathrm{a}}$ & $18.150 \pm 1.814^{\mathrm{a}}$ & $11.444 \pm 6.579^{\mathrm{b}}$ & $<0.001$ \\
\hline Ewing score & $0.089 \pm 0.193^{\mathrm{a}}$ & $1.0 \pm 0.0^{\mathrm{b}}$ & $2.0 \pm 0.0^{c}$ & $3.556 \pm 0.504^{\mathrm{d}}$ & $<0.001$ \\
\hline
\end{tabular}

Table 5. Ewing's tests values of diabetic patients (using ANOVA test). CAN = cardiac autonomic neuropathy; $\mathrm{HR}=$ heart rate; $\mathrm{E}: \mathrm{I}=$ expiration: inspiration; $\mathrm{BP}$ = blood pressure, Different small letters indicate significant differences.

definite CAN and $36.11 \%$ had severe CAN. In people with diabetes with $>10$ duration of illness, none of them had early CAN, $20 \%$ had definite CAN, and 63.89\% had severe CAN $(p=0.001)$.

Table 5 showed the values of different Ewing's tests in people with diabetes according to the stage of CAN. It was obvious that there was a significant difference between the four stages of CAN. Moreover, the Ewing score was significantly increased as CAN staging become more severe.

CAN severity, demographic \& clinical data. Using Pearson's correlation test, Fig. 2 (A-E) shows a positive correlation between CAN severity and patient age $(\mathrm{r}=0.439, p<0.001)$, duration of diabetes $(\mathrm{r}=0.891$, $p<0.001)$, WHR $(\mathrm{r}=0.224, p<0.001)$, HbAlc $(\mathrm{r}=0.479, p<0.001)$, and WHR $(\mathrm{r}=0.224, p<0.001)$. On the contrary, there was no significant correlation between the CAN severity and the BMI $(r=0.142, p>0.136)$.

Association of CAN with demographic features of people with diabetes. Of the seven characteristics of people with diabetes, three were found to be significantly associated with CAN when tested separately. These were the age, duration of diabetes, and HbAlc level. However, using multivariate regression analysis is used to test all characteristics together; only the duration of diabetes and HbAlc level appear to be associated with CAN development (Table 6).

Approximately $57 \%$ of patients with diabetes duration $\geq 7.5$ years were CAN positive compared to only $42.67 \%$ of patients with duration $<7.5$ years and CAN positive $(\mathrm{OR}=10.63,95 \% \mathrm{Cl}=2.56-44.06)$. Likewise, the majority of patients $(78.67 \%)$ with $\mathrm{HbAlc} \geq 8.0$ developed CAN compared to only about one-fourth of those with $\mathrm{HbAlc}<8.0$ who developed this a complication $(\mathrm{OR}=4.25,95 \% \mathrm{Cl}=1.45-12.43)$.

\section{Discussion}

The study population. Cardiovascular autonomic tests. People with diabetes show significantly abnormal cardiac autonomic tests (from 14.79 to $50 \%$ ) compared to 0 to $4 \%$ of control subjects. Other researchers ${ }^{14,15}$ record similar results, but with slightly different percentages that could be due to the CAN adoption criteria, patient sample size, disease length, and ethnicity.

This tendency of people with diabetes to develop CAN is attributed to complex interactions between several mechanisms and pathways leading to neuronal ischemia and finally neuronal death ${ }^{16,17}$.

Hyperglycemia is the leading cause of diabetes-related CAN. This induces oxidative stress and toxic advanced glycosylation products which ultimately result in neuronal dysfunction and increases mitochondrial production of free reactive oxygen species, causing oxidative damage to the microvasculature that supplies these peripheral nerves. These different pathways induce changes in gene expression, transcription factors, interruption of several cell functions, and communication between the cells and the surrounding matrix. All this leads to neuronal dysfunction and death ${ }^{16,18}$

Like somatic neuropathies, some investigators have shown that autonomic nerves may be affected in a lengthdependent manner ${ }^{17}$. As a result, CAN often first manifests itself in the vagus nerve, the longest parasympathetic autonomic nerve in the body, and the one responsible for nearly three-quarters of parasympathetic activity. Compassionate denervation occurs at the later stage of $\mathrm{CAN}^{19}$.

People with diabetes in this cohort showed significantly reduced HR response to deep breathing (E:I ratio), $\mathrm{HR}$ response to standing (30:15 ratio), BP response to handgrip testing, and orthostatic hypotension. These findings have also been demonstrated by others ${ }^{20-22}$.

The people with diabetes. The clinical data. In our study, approximately $53 \%$ of the people with diabetes presented with CAN, were within the range $(15.3 \%$ to $61.6 \%)$ registered worldwide ${ }^{23-25}$. This wide range is due to the variability of diagnostic criteria, and tests used among T2DM patients.

Our study revealed a non-significant difference in the mean age of the diabetics with and without CAN which denotes no relationship between CAN and age ${ }^{25,26}$. Other groups of researchers have seen almost the same age incidence $\mathrm{e}^{25,27}$.

Although not statistically significant, women had a higher prevalence of CAN than men in this study (56\% vs. $44 \%$ ). Approximately similar results have been reported by others ${ }^{25,28}$. The gender impacts on CAN 
a

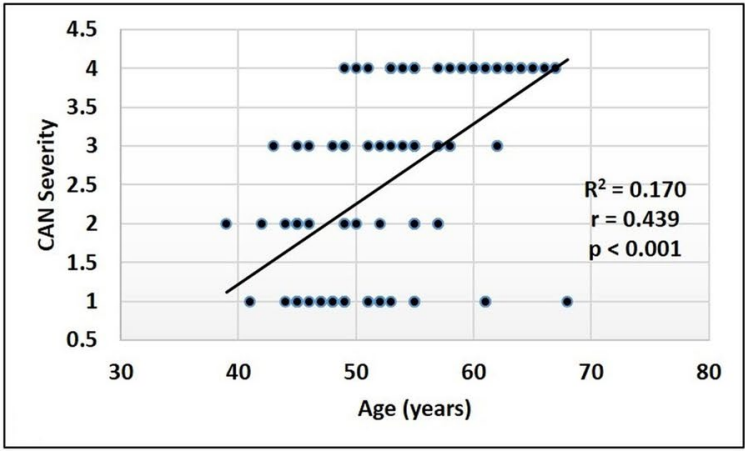

C

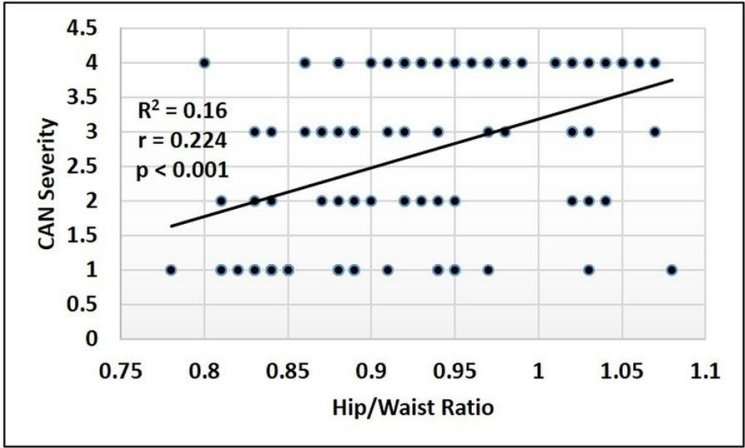

b

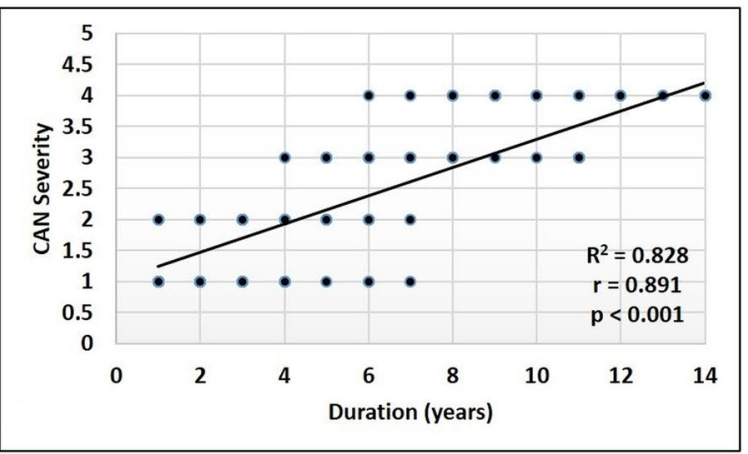

d

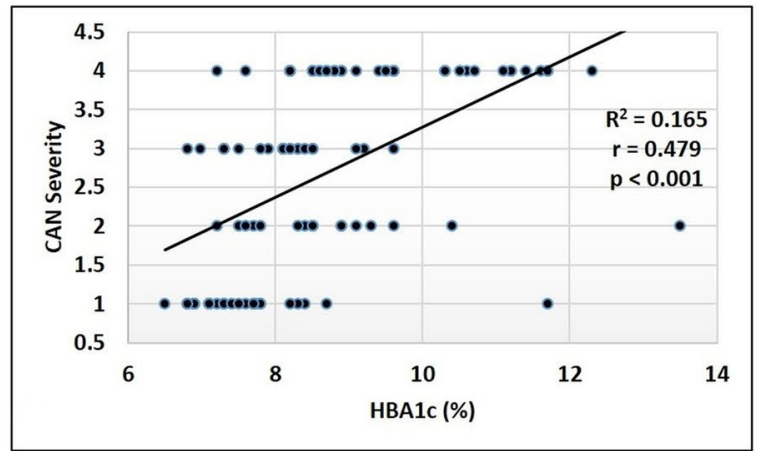

e

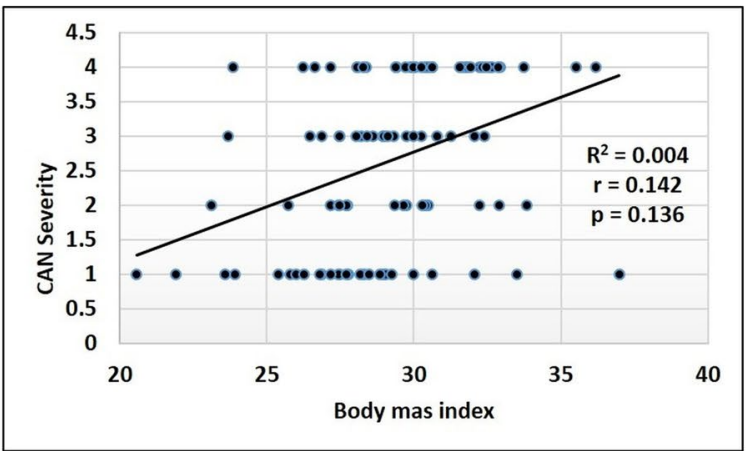

Figure 2. (A) correlation between CAN severity and patient's age (B) correlation between CAN severity and diabetes duration (C) correlation between CAN severity and waist-hip ratio (D) Correlation between CAN severity and HbAlc level (E) Correlation between CAN severity and body mass index.

epidemiology is controversial. In the Action to Control Cardiovascular Risk in Diabetes (ACCORD) study, which included > 8,000 patients with T2DM, a higher prevalence of CAN was found in women compared to men ${ }^{19}$. A more recent study, although not statistically significant, also showed that women had a higher prevalence of CAN than men $(65.2 \% \text { vs. } 34.8 \%, p=0.059)^{29}$. However, in a multi-center, cross-sectional study of 3,250 people with diabetes, the prevalence of CAN was not different between males and males (35\% male vs. $37 \%$ female $)^{30}$. Other studies showed no difference in CAN prevalence between men and women ${ }^{26,31,32}$.

In our study, the prevalence of CAN increases as the duration of diabetes increases (beyond 6 years and more) and also with poorer glycemic control (6.5-8.4\% and $>8.4 \%)$. In their studies, Pop-Busui ${ }^{19}$, Spallone et al. ${ }^{7}$, Moningi et al. ${ }^{33}$, and Bhuyan et al. ${ }^{34}$ have shown that the longer duration of diabetes is independently associated with CAN. Ahire et al..$^{35}$ found a positive correlation between CAN and the duration of diabetes, as those with a duration of $>5$ years are more likely to have a definite and severe CAN than those with a duration of $<5$ years. Also, early CAN was commonly seen in patients with a shorter duration of disease. The incidence of CAN was reported to be $2 \%$ annually in patients with $\mathrm{T}_{2} \mathrm{DM}^{16}$ and the prevalence increased from 9 to $31 \%$ 1 year later ${ }^{23}$. In addition, Dimova et al. ${ }^{36}$ found that prevalence increased from $19.8 \%$ in pre-diabetics to $32.2 \%$ in newly diagnosed patients with T2DM, with the higher prevalence reported in patients with T2DM and longer duration of disease. The increased prevalence of CAN with a longer duration of the disease can be attributed to the fact that patients often have a history of many years without symptoms during which blood glucose peaks occur unnoticed, but diabetes is not yet diagnosed and treated. Thus, in T2DM, complications of diabetes may occur at the time of the initial presentation. 


\begin{tabular}{|c|c|c|c|c|c|}
\hline \multirow[b]{2}{*}{ Variables } & \multicolumn{2}{|l|}{ CAN } & \multirow[b]{2}{*}{$\begin{array}{l}\text { Crude } \\
\text { p-value }\end{array}$} & \multirow[b]{2}{*}{$\begin{array}{l}\text { Adjusted } \\
\text { p-value }\end{array}$} & \multirow[b]{2}{*}{ OR $(95 \% \mathrm{CI})$} \\
\hline & $\begin{array}{l}\text { Positive } \\
(\mathrm{n}=75)\end{array}$ & $\begin{array}{l}\text { Negative } \\
(n=67)\end{array}$ & & & \\
\hline \multicolumn{6}{|c|}{ Age (years) } \\
\hline$<50$ & $16(21.33 \%)$ & $31(46.26 \%)$ & 0.002 & 0.154 & 1.0 Reference \\
\hline$\geq 50$ & $59(78.67 \%)$ & $36(53.7 \%)$ & & & $2.21(0.74-6.57)$ \\
\hline \multicolumn{6}{|l|}{ Gender } \\
\hline Male & $33(44 \%)$ & $29(43.28 \%)$ & 0.932 & 0.409 & 1.0 Reference \\
\hline Female & $42(56 \%)$ & $38(56.72 \%)$ & & & $0.63(0.21-1.89)$ \\
\hline \multicolumn{6}{|c|}{ BMI $\left(\mathrm{Kg} / \mathbf{m}^{2}\right)$} \\
\hline$<30$ & $41(54.67 \%)$ & $41(84 \%)$ & 0.432 & 0.492 & 1.0 Reference \\
\hline$\geq 30$ & $34(45.33 \%)$ & $26(16 \%)$ & & & $1.56(0.44-5.57)$ \\
\hline \multicolumn{6}{|l|}{ WHR } \\
\hline$<0.9$ & $27(36 \%)$ & $32(68 \%)$ & 0.156 & 0.575 & 1.0 Reference \\
\hline$\geq 0.9$ & $48(64 \%)$ & $35(32 \%)$ & & & $0.58(0.09-3.93)$ \\
\hline \multicolumn{6}{|l|}{ Smoking } \\
\hline Yes & $22(29.33 \%)$ & $12(16 \%)$ & 0.111 & 0.318 & 1.0 Reference \\
\hline No & $53(70.67 \%)$ & $55(84 \%)$ & & & $0.94(0.12-7.28)$ \\
\hline \multicolumn{6}{|c|}{ Duration (years) } \\
\hline$<7.5$ & $32(42.67 \%)$ & $62(100 \%)$ & $<0.001$ & 0.001 & 1.0 Reference \\
\hline$\geq 7.5$ & $43(57.33 \%)$ & $5(0 \%)$ & & & $10.63(2.56-44.06)$ \\
\hline \multicolumn{6}{|l|}{ HbAlc\% } \\
\hline$<8.0$ & $16(21.33 \%)$ & $54(84 \%)$ & $<0.001$ & 0.008 & 1.0 Reference \\
\hline$\geq 8.0$ & $59(78.67 \%)$ & $13(16 \%)$ & & & $4.25(1.45-12.43)$ \\
\hline
\end{tabular}

Table 6. Predictors of cardiac autonomic neuropathy (using multiple regression). $\mathrm{CAN}=$ cardiac autonomic neuropathy; $\mathrm{BMI}=$ body mass index; $\mathrm{WHR}=$ waist-hip ratio.

CAN staging. Compared to the patients with early or definite CAN, patients with severe CAN were older at the time of the study $(\mathrm{p}=0.028)$, had longer diabetes duration, and poorer glycemic control than HbAlc indexed. Yun et al. ${ }^{37}$ study the progression of CAN and its association with other risk factors in 578 people with diabetes. They noted a significant association with age, glycemic control, and disease duration. Generally, "aging of regulatory systems" in people with diabetes with CAN is 10 years earlier than the biological age of the patient ${ }^{38}$. This confirms the hypothesis that the aging of the autonomic system in addition to endothelial dysfunction is one of the most important reasons for the early onset of atherosclerosis and associated cardiovascular disease. Yun et al. ${ }^{39}$ and Lai et al. ${ }^{40}$ examined diabetics with CAN and observed delayed, sympathetic and parasympathetic activation in response to fluctuations in blood glucose levels. This study showed a step-by-step increase in the risk of developing higher HbAlc variability based on CAN severity, suggesting a dose-dependent negative CAN influence. The complementary interaction of the hormones and peptides involved in glucose homeostasis is usually more disrupted as diabetes progresses, and subjects are likely to show a high increase in glucose levels from external stimuli. The effect of CAN on glucose fluctuations could, therefore be more pronounced in subjects with long-term diabetes ${ }^{41}$.

Cardiovascular autonomic tests. In general, there was a significant difference between people with diabetes with and without CAN in the results of the Ewing tests. In line with this finding, Lin et al. ${ }^{21}$ examined 90 people with diabetes with and without CAN and found the same difference.

Autonomous innervation is the primary extrinsic control mechanism that regulates HRV and cardiac performance. Chronic hyperglycemia has been shown to promote progressive autonomic neural dysfunction in a manner that parallels the development of peripheral neuropathy ${ }^{16,19}$.

The criterion for CAN severity was an increase of at least one point in the Spallone score. The E/I ratio, the 30:15 ratio, and the sustained handgrip were significantly reduced while the BP response to standing was increased. These cardiovascular autonomic changes are expected to have a longer duration of diabetes due to the impact of CAN severity ${ }^{42}$.

This study found a significant correlation between CAN and glycemic control, duration of diabetes, and WHR, but not BMI. These findings underscore the role of insulin resistance not only in the etiology of metabolic syndrome but also as a determinant of cardiac autonomic dysfunction. These findings are consistent with the reports by Laitinen et $\mathrm{al}^{43}$, and Moţăăăianu et al. ${ }^{44}$.

Absent BMI and CAN correlations may be explained by the fact that BMI quantifies general adiposity; although individuals who are overweight or obese are likely to have excess fat, BMI does not indicate how this fat is distributed in the body. Welborn and Dhaliwal ${ }^{45}$ and Srikanthan et al. ${ }^{46}$ have confirmed that WHR is a superior clinical measure for predicting all-cause and cardiovascular disease mortality. 
Contrary to our study, no relationship was found in a recent study in Iran between the CAN and the glycemic control level ${ }^{47}$. They argued that this could be due to several reasons that could affect outcomes such as criteria for tight control of diabetes, duration of diabetes, metabolic memory, sample size, and the CAN diagnostic method.

Of interest based on positive Ewing tests, we found that the parameters used to evaluate parasympathetic functions were abnormal (positive) in $56(39.44 \%)$ compared to $36(25.35 \%)$. It may indicate that parasympathetic dysfunction is more sensitive to the detection of autonomic dysfunction. These percentages were slightly different from those registered worldwide, yet they were harmonized ${ }^{14,21}$.

Effect of demographic features on the development of CAN. With multivariate regression analysis to test age, gender, BMI, HWR, smoking, HbAlc level, and disease duration, only the duration of diabetes and HbA1c level appear to be associated with CAN development. This is partly in agreement with the findings of others ${ }^{7,29}$ who used clinical and laboratory predictors.

\section{Conclusion}

CAN is common among people with diabetes (52.82\%), the poorer the glycemic control and the longer the duration of the disease, the higher the incidence of CAN in T2DM. Age, duration of disease, WHR, and HbA1c are well correlated with the severity of CAN. Parasympathetic impairment is more sensitive to the detection of autonomic dysfunction.

CAN is a significant DM complication and is closely associated with increased risk of cardiovascular mortality. While it is a popular complication, its importance has not been fully understood in our societies and still hot field for research because: (A) The impact of sex on CAN epidemiology is controversial. (B) The effect of ethnicity on CAN prevalence is controversial and little to nothing has been done in Arabs to the best of our knowledge.

(C) CAN pathogenesis is complex, multifactorial, and still under much debate. (D) Smoking, obesity, and lifestyle are among the risk factors and were certainly different between societies (Arab versus western countries)".

\section{Data sharing statement}

All relevant data are within the manuscript and its Supporting Information files.

\section{Data availability}

The data that support the findings of this study are available from the corresponding author upon reasonable request.

Received: 4 July 2020; Accepted: 29 December 2020

Published online: 11 February 2021

\section{References}

1. Punthakee, Z., Goldenberg, R. \& Katz, P. Definition, classification and diagnosis of diabetes, prediabetes and metabolic syndrome (Diabetes Canada Clinical Practice Guidelines Expert Committee). Can. J. Diabetes 42(Suppl 1), S10-S15. https://doi.org/10.1016/j. jcjd.2017.10.003 (2018).

2. Razmaria, A. A. Diabetic neuropathy. JAMA 314(20), 2202. https://doi.org/10.1001/jama.2015.15899 (2015).

3. Vinik, A. I., Erbas, T. \& Casellini, C. M. Diabetic cardiac autonomic neuropathy, inflammation and cardiovascular disease. J. Diabetes Investig. 4, 4-18. https://doi.org/10.1111/jdi.12042 (2013).

4. Serhiyenko, V. A. \& Serhiyenko, A. A. Cardiac autonomic neuropathy: Risk factors, diagnosis and treatment. World J. Diabetes 9(1), 1-24. https://doi.org/10.4239/wjd.v9.i1.1 (2018).

5. Pop-Busui, R. et al. Association between cardiovascular autonomic neuropathy and left ventricular dysfunction: DCCT/EDIC study (Diabetes Control and Complications Trial/Epidemiology of Diabetes Interventions and Complications). J. Am. Coll. Cardiol. 61, 447-454. https://doi.org/10.1016/j.jacc.2012.10.028 (2013).

6. Pop-Busui, R. et al. Diabetic neuropathy: a position statement by the American diabetes association. Diabetes Care 40, 136-154. https://doi.org/10.2337/dc16-2042 (2017).

7. Spallone, V. et al. Cardiovascular autonomic neuropathy in diabetes: clinical impact, assessment, diagnosis, and management. Diabetes Metab. Res. Rev. 27, 639-653. https://doi.org/10.1002/dmrr.1239 (2011).

8. Ziegler, D. et al. Increased prevalence of cardiac autonomic dysfunction at different degrees of glucose intolerance in the general population: the KORA S4 survey. Diabetologia 58, 1118-1128. https://doi.org/10.1007/s00125-015-3534-7 (2015).

9. Jaiswal, M. et al. Association between impaired cardiovascular autonomic function and hypoglycemia in patients with type 1 diabetes. Diabetes Care 37(9), 2616-2621. https://doi.org/10.2337/dc14-0445 (2014).

10. American Diabetes Association. Classification and diagnosis of diabetes: standards of medical care in diabetes-2018. Diabetes Care 42(Suppl 1), S13-S28 (2019).

11. Qiong, Y. U. et al. Appropriate body mass index and waist-hip ratio cutoff points for overweight and obesity in adults of Northeast China. Iran J. Public Health 46(8), 1038-1045 (2017).

12. Wang, H. F., Chen, Y. C., Yang, F. H. \& Juan, C. W. Relationship between type 2 diabetes self- efficacy and quality of life: Analysis under varying glycated hemoglobin conditions. Family Med. Med. Sci. Res. 6(2), 218-228. https://doi.org/10.4172/2327-4972.10002 18 (2017).

13. Spallone, V. et al. Recommendations for the use of cardiovascular tests in diagnosing diabetic autonomic neuropathy. Nutr. Metab. Cardiovasc. Dis. 21(1), 69-78. https://doi.org/10.1016/j.numecd.2010.07.005 (2011).

14. Pathak, A., Gupta, S., Kumar, S. \& Agrawal, S. Evaluation of cardiovascular autonomic nervous functions in diabetics: study in a rural teaching hospital. J. Pract. Cardiovasc. Sci. 3, 150-157. https://doi.org/10.4103/jpcs.jpcs_50_17 (2017).

15. Menon, A. S., Dixit, A., Garg, M. K. \& Girish, R. Cardiac autonomic neuropathy in patients with type 2 diabetes mellitus at high risk for foot ulcers. Indian J. Endocrinol. Metab. 21(2), 282-285. https://doi.org/10.4103/ijem.IJEM_542_16 (2017).

16. Dimitropoulos, G., Tahrani, A. A. \& Stevens, M. J. Cardiac autonomic neuropathy in patients with diabetes mellitus. World J. Diabetes 5(1), 17-39. https://doi.org/10.4239/wjd.v5.11.17 (2014).

17. Balcığlu, A. S. \& Müderrisoğlu, H. Diabetes and cardiac autonomic neuropathy: clinical manifestations, cardiovascular consequences, diagnosis and treatment. World J. Diabetes 6, 80-91. https://doi.org/10.4239/wjd.v6.i1.80 (2015).

18. Albers, J. W. \& Pop-Busui, R. Diabetic neuropathy: mechanisms, emerging treatments, and subtypes. Curr. Neurol. Neurosci. Rep. 14(8), 473. https://doi.org/10.1007/s11910-014-0473-5 (2014). 
19. Pop-Busui, R. Cardiac autonomic neuropathy in diabetes: a clinical perspective. Diabetes Care 33(2), 434-441. https://doi. org/10.2337/dc09-1294 (2010).

20. Pafili, K., Trypsianis, G., Papazoglou, D., Maltezos, E. \& Papanas, N. Simplified diagnosis of cardiovascular autonomic neuropathy in type 2 diabetes using Ewing's battery. Rev Diabetes Stud. 12(1-2), 213-219. https://doi.org/10.1900/RDS.2015.12.213 (2015).

21. Lin, K., Wei, L., Huang, Z. \& Zeng, Q. Combination of Ewing test, heart rate variability, and heart rate turbulence analysis for early diagnosis of diabetic cardiac autonomic neuropathy. Medicine (Baltimore) 96(45), e8296. https://doi.org/10.1097/MD.0000000000 008296 (2017).

22. Dixit, P. N., Itagi, V., Babu, R. Y. \& Prakash, S. B. Effect of diabetes mellitus on resting heart rate, postural blood pressure, Valsalva ratio, and blood pressure response to handgrip test. Natl. J. Physiol. Pharm. Pharmacol. 8(10), 1441-1445. https://doi.org/10.5455/ njppp.2018.8.0722924072018 (2018).

23. Pop-Busui, R. et al. Cardiovascular autonomic neuropathy and cardiovascular outcomes in the Diabetes Control and Complications Trial/Epidemiology of Diabetes Interventions and Complications (DCCT/EDIC) study. Diabetes Care 40(1), 94-100. https ://doi.org/10.2337/dc16-1397 (2017).

24. Memon, A. Cardiac autonomic neuropathy in type 2 diabetes mellitus using Bellavere's score system. Int. J. Health Sci. (Qassim) 11(5), 26 (2017).

25. AlOlaiwi, L. A., AlHarbi, T. J. \& Tourkmani, A. M. Prevalence of cardiovascular autonomic neuropathy and gastroparesis symptoms among patients with type 2 diabetes who attend a primary health care center. PLoS ONE 13(12), e0209500. https://doi.org/10.1371/ journal.pone.0209500 (2018)

26. Pillai, J. N. \& Madhavan, S. Cardiac autonomic neuropathy and QTc interval in type 2 diabetes. Heart India 3(1), 8-11. https:// doi.org/10.4103/2321-449X.153279 (2015).

27. Röhling, M., Strom, A., Bönhof, G. J., Roden, M. \& Ziegler, D. Cardiorespiratory fitness and cardiac autonomic function in diabetes. Curr. Diabetes Res. 17(12), 125. https://doi.org/10.1007/s11892-017-0959-z (2017).

28. Cha, S. A. et al. Diabetic cardiovascular autonomic neuropathy predicts recurrent cardiovascular diseases in patients with type 2 diabetes. PLoS ONE 11(10), e0164807. https://doi.org/10.1371/journal.pone.0164807 (2016).

29. Tannus, L. R., Drummond, K. R., Clemente, E. L., da Matta, M. F. \& Gomes, M. B. Predictors of cardiovascular autonomic neuropathy in patients with type 1 diabetes. Front. Endocrinol. (Lausanne) 5, 191. https://doi.org/10.3389/fendo.2014.00191 (2014).

30. Kempler, P. et al. Autonomic neuropathy is associated with increased cardiovascular risk factors: the EURODIAB IDDM Complications Study. Diabetes Med. 19(11), 900-909. https://doi.org/10.1046/j.1464-5491.2002.00821.x (2002).

31. Chung, J. O., Park, S. Y., Cho, D. H., Chung, D. J. \& Chung, M. Y. Anemia, bilirubin, and cardiovascular autonomic neuropathy in patients with type 2 diabetes. Medicine (Baltimore). 96(15), e6586. https://doi.org/10.1097/MD.0000000000006586 (2017).

32. Behera, B. K. \& Vishnu, K. Cardiac autonomic neuropathy in diabetes mellitus. Int. J. Res. Med. Sci. 6(1), 88-93. https://doi. org/10.18203/2320-6012.ijrms20175501 (2018).

33. Moningi, S., Nikhar, S. \& Ramachandran, G. Autonomic disturbances in diabetes: Assessment and anaesthetic implications. Indian J. Anaesth. 62(8), 575-583. https://doi.org/10.4103/ija.IJA_224_18 (2018).

34. Bhuyan, A. K., Baro, A., Sarma, D. \& Choudhury, B. A study of cardiac autonomic neuropathy in patients with type 2 diabetes mellitus: a Northeast India experience. Indian J. Endocrinol. Metab. 23(2), 246. https://doi.org/10.4103/ijem.IJEM_336_18 (2019).

35. Ahire, C., Sarode, V., Jadhav, K., Shreeram, V. \& Gaidhani, N. Prevalence of cardiac autonomic neuropathy in short and longstanding type 2 diabetics in western Maharashtra. Indian J. Basic Appl. Med. Res. 3(4), 252-259 (2014).

36. Dimova, R. et al. Risk factors for autonomic and somatic nerve dysfunction in different stages of glucose tolerance. J. Diabetes Complicat. 31(3), 537-543. https://doi.org/10.1016/j.jdiacomp.2016.11.002 (2017).

37. Yun, J. S., Park, Y. M., Cha, S. A., Ahn, Y. B. \& Ko, S. H. Progression of cardiovascular autonomic neuropathy and cardiovascular disease in type 2 diabetes. Cardiovasc. Diabetol. 17(1), 109. https://doi.org/10.1186/s12933-018-0752-6 (2018).

38. Kurnikova, I. A., Kisliy, N. D., Kislaya, S. N. \& Sargar, R. Autonomic neuropathy in the development and progression of vascular complications of diabetes mellitus. Neurol. Neurosci. Rep. 1(2), 1-5. https://doi.org/10.15761/NNR.1000111 (2018).

39. Yun, J. S. et al. Cardiovascular autonomic dysfunction predicts severe hypoglycemia in patients with type 2 diabetes: a 10-year follow-up study. Diabetes Care 37(1), 235-241. https://doi.org/10.2337/dc13-1164 (2014).

40. Lai, Y. R. et al. HbA1C variability is strongly associated with the severity of cardiovascular autonomic neuropathy in patients with Type 2 diabetes after longer diabetes duration. Front Neurosci. 13, 458. https://doi.org/10.3389/fnins.2019.00458 (2019).

41. Prentki, M. \& Nolan, C. J. Islet beta-cell failure in type 2 diabetes. J. Clin. Investig. 116(7), 1802-1812. https://doi.org/10.1172/ JCI29103 (2006).

42. Makwana, K., Kalasava, K. \& Mehta, H. Prognosis of cardiac autonomic neuropathy in patients with diabetes mellitus. Int. J. Diabetes Res. 2(1), 1-5 (2013).

43. Laitinen, T. et al. Cardiovascular autonomic dysfunction is associated with central obesity in persons with impaired glucose tolerance. Diabetes Med. 28(6), 699-704. https://doi.org/10.1111/j.1464-5491.2011.03278.x (2011).

44. Moţăţăianu, A., Bălaşa, R., Voidăzan, S. \& Bajkó, Z. Cardiovascular autonomic neuropathy in context of other complications of type 2 diabetes mellitus. Biomed. Res. Int. 2013, 507216. https://doi.org/10.1155/2013/507216 (2013).

45. Welborn, T. A. \& Dhaliwal, S. S. Preferred clinical measures of central obesity for predicting mortality. Eur. J. Clin. Nutr. 61(12), 1373-1379. https://doi.org/10.1038/sj.ejcn.1602656 (2007).

46. Srikanthan, P., Seeman, T. E. \& Karlamangla, A. S. Waist-hip-ratio as a predictor of all-cause mortality in high functioning older adults. Ann. Epidemiol. 19(10), 724-731. https://doi.org/10.1016/j.annepidem.2009.05.003 (2009).

47. Vasheghani, M., Sarvghadi, F. \& Beyranvand, M. R. The association between cardiac autonomic neuropathy and diabetes control. Diabetes Metab. Syndr. Obes. 12, 581-587. https://doi.org/10.2147/DMSO.S196729 (2019).

\section{Acknowledgments}

The authors are grateful to the volunteers and their medical providers for participating in this study.

\section{Author contributions}

M.M.D. and F.B.H. conceived of the presented idea and constructed the design of this study, performed all statistical analyses, and drafted the manuscript. M.S.K. examined and referred the people with diabetes, H.Y.A.-M. collaborated on the statistical analyses and helped to compose and edit the manuscript. All authors read and approved the final manuscript.

\section{Funding}

This research was personally funded. This research did not receive any specific grant from any organization.

\section{Competing interests}

The authors declare no competing interests. 


\section{Additional information}

Correspondence and requests for materials should be addressed to H.Y.A.-M.

Reprints and permissions information is available at www.nature.com/reprints.

Publisher's note Springer Nature remains neutral with regard to jurisdictional claims in published maps and institutional affiliations.

(c) (i) Open Access This article is licensed under a Creative Commons Attribution 4.0 International License, which permits use, sharing, adaptation, distribution and reproduction in any medium or format, as long as you give appropriate credit to the original author(s) and the source, provide a link to the Creative Commons licence, and indicate if changes were made. The images or other third party material in this article are included in the article's Creative Commons licence, unless indicated otherwise in a credit line to the material. If material is not included in the article's Creative Commons licence and your intended use is not permitted by statutory regulation or exceeds the permitted use, you will need to obtain permission directly from the copyright holder. To view a copy of this licence, visit http://creativecommons.org/licenses/by/4.0/.

(C) The Author(s) 2021 